\title{
A case of chlamydia psittaci caused severe pneumonia and meningitis diagnosed by metagenome next-generation sequencing and clinical analysis: a case report and literature review
}

Yunfeng Shi ${ }^{1,2+}$, Junxian Chen ${ }^{1,2+}$, Xiaohan Shi ${ }^{1,2^{*}}$, Jiajia Hu ${ }^{1,2}$, Hongtao $\mathrm{Li}^{1,2}$, Xiaojie $\mathrm{Li}^{3}$, Yanhong Wang ${ }^{1,2}$ and Benquan $\mathrm{Wu}^{1,2^{*}}$ (D)

\begin{abstract}
Background: Psittacosis, which is also known as parrot fever, is Chlamydia psittaci (C. psittaci) caused infectious disease. The clinical manifestations vary from asymptomatic infection to severe atypical pneumonia or even fatal meningitis. Early recognition of psittacosis is difficult because of its nonspecific clinical manifestations. Culture and gene probe techniques for C. psittaci are not available for routine clinical use, which makes the diagnosis difficult too. Although psittacosis has increasingly been recognized and reported in recent years, cure of severe pneumonia complicated with meningitis, with etiologic diagnosis aided by the use of metagenomic next-generation sequencing (mNGS), is still uncommon. So, it is necessary to report and review such potentially fatal case.

Case presentation: This report describes a 54-year-old woman with C. psittaci caused severe atypical pneumonia and meningitis. She presented with symptoms of fever, dry cough and dyspnea, accompanied by prominent headache. Her condition deteriorated rapidly to respiratory failure and lethargy under the treatment of empirical antibacterial agents, and was treated with invasive mechanical ventilation soon. She denied contact with birds, poultry or horses, but unbiased mNGS of both the bronchoalveolar lavage fluid (BALF) and the cerebrospinal fluid (CSF) identified sequence reads corresponding to C. psittaci infection, and there was no sequence read corresponding to other probable pathogens. Combined use of targeted antimicrobial agents of tetracyclines, macrolides and fluoroquinolones was carried out, and the patient's condition improved and she was discharged home 28 days later. Her status returned close to premorbid condition on day 60 of follow-up.
\end{abstract}

\footnotetext{
* Correspondence: shiningxh@yeah.net; zswbq@163.com

'Yunfeng Shi and Junxian Chen contributed equally to this work.

'Medical Intensive Care Unit, Department of Respiratory and Critical Care

Medicine, Third Affiliated Hospital of Sun Yat-Sen University, Guangzhou

510630, China

Full list of author information is available at the end of the article
}

C C The Author(s). 2021 Open Access This article is licensed under a Creative Commons Attribution 4.0 International License, which permits use, sharing, adaptation, distribution and reproduction in any medium or format, as long as you give appropriate credit to the original author(s) and the source, provide a link to the Creative Commons licence, and indicate if changes were made. The images or other third party material in this article are included in the article's Creative Commons licence, unless indicated otherwise in a credit line to the material. If material is not included in the article's Creative Commons licence and your intended use is not permitted by statutory regulation or exceeds the permitted use, you will need to obtain permission directly from the copyright holder. To view a copy of this licence, visit http://creativecommons.org/licenses/by/4.0/ The Creative Commons Public Domain Dedication waiver (http://creativecommons.org/publicdomain/zero/1.0/) applies to the data made available in this article, unless otherwise stated in a credit line to the data. 
Conclusions: When clinicians come across a patient with atypical pneumonia accompanied by symptoms of meningitis, psittacosis should be taken into consideration. mNGS is a promising detection method in such condition and is recommended.

Keywords: Psittacosis, Chlamydia psittaci, Severe pneumonia, Meningitis, Metagenome next-generation sequencing, Case report

\section{Background}

Human psittacosis, also known as parrot fever or ornithosis, is a zoonotic infectious disease whose agent is the obligate intracellular bacterium Chlamydia psittaci $(C$. psittaci). Although psittacosis is not a common disease, it has been reported worldwide, including China, USA, Europe, and especially in Australia [1-4]. It accounts for $1-2 \%$ of cases of community-acquired pneumonia (CAP) annually [5]. However, the clinical manifestations vary from asymptomatic infection to fatal systemic illness [3]. There is no convenient and specific test for identification of $C$. psittaci. In recent years, with the improvement in detection methods and understanding of the disease, increased cases of psittacosis have been reported. Here, we present a successfully cured case of severe pneumonia and meningitis caused by C. psittaci, with etiologic diagnosis aided by the use of metagenomic next-generation sequencing (mNGS). To the best of our knowledge, this is the first case of such infection caused by $C$. psittaci and detected by mNGS in time with good outcome.

\section{Case presentation}

The patient was admitted to our hospital because of recurrent headache and fever for $20 \mathrm{~d}$ and dyspnea for 3 $\mathrm{d}$. She presented with headache $20 \mathrm{~d}$ before admission, which consisted of tolerable fluctuating pain in the left occipital region, which last 2-3 min every attack and resolved naturally. Low-grade fever (unmeasured temperature) was present from the next day, accompanied by sore throat and dry cough without sputum. There was no chills, muscle soreness or limb weakness. After oral drug treatment (unknown) prescribed by local hospital, sore throat and dry cough were relieved temporarily. Fever recurred at $15 \mathrm{~d}$ before admission with a temperature of $38^{\circ} \mathrm{C}$, accompanied by obvious fatigue, dry cough, nausea and non-projectile vomiting of gastric contents three or four times per day. About $1 \mathrm{w}$ before admission, the patient suffered long-term memory loss, bilateral hearing loss and limb weakness. Urinary incontinence occurred on the next day, without syncope, loss of consciousness, and general tics. Three days before admission, the patient had dyspnea, and her previous symptoms became aggravated, so she was sent immediately to the emergency department of the Third Affiliated Hospital of Sun Yat-Sen University. During the progress of routine examination in the emergency department, her condition deteriorated rapidly to severe hypoxemia and lethargy. After tracheal intubation and ventilator assisted ventilation, she was transferred to the medical intensive care unit (MICU) for further treatment.

The patient suffered from hypothyroidism for 5 years and regularly took oral levothyroxine (Euthyrox $25 \mathrm{mg} /$ d). She also had hepatitis B and was treated with entecavir $0.5 \mathrm{mg} / \mathrm{d}$ regularly. Her thyroid function and liver function were normal during regular out-patient visit. She had no diabetes mellitus, head trauma, or psychiatric or psychological disease. She had no tuberculosis or lung cancer. She is neither a smoker nor a drug addict. She resides in Guangdong province, southern China. She had no recent travel, tick bites, or acute upper respiratory infection. She had not been in contact with any birds, poultry or horses directly. She didn't shop at live-bird markets, nor had friends or relatives with pet birds.

When the patient was admitted to MICU (day 1), her vital signs were as follows: body temperature $39.0^{\circ} \mathrm{C}$, pulse rate 128 beats/min, respiratory rate 20 breaths/ min, blood pressure $105 / 78 \mathrm{mmHg}$ with administration of dopamine $6 \mu \mathrm{g} /(\mathrm{kg} \cdot \mathrm{min})$ via micro pump, and pulse oxygen saturation $96.4 \%$ with a fraction of inspired oxygen $\left(\mathrm{FiO}_{2}\right)$ of 0.90 . The patient presented with lethargy while under treatment with sedation. The rough breath sounds and wet rales on both lungs were heard on auscultation. There was no audible murmur on cardiac auscultation. Tenderness and hepatosplenomegaly were not detected. She had no neck stiffness. Kernig sign was suspicious positive. No rash was observed.

Laboratory data upon admission to MICU revealed white blood cell $(\mathrm{WBC})$ count $6.37 \times 10^{9} / \mathrm{L}$ with an elevated neutrophil ratio of $94.7 \%$. The concentration of C-reactive protein (CRP) and procalcitonin (PCT) were $175.0 \mathrm{mg} / \mathrm{L}$ and $6.87 \mathrm{ng} / \mathrm{mL}$, respectively. Erythrocyte sedimentation rate (ESR) was $65 \mathrm{~mm} / \mathrm{h}$. Lactate was 1.3 $\mathrm{mmol} / \mathrm{L}$. Electrolytes and creatinine were within normal limits. Albumin level was $29.4 \mathrm{~g} / \mathrm{L}$. Aspartate aminotransferase (AST) was $218 \mathrm{U} / \mathrm{L}$ and alanine aminotransferase (ALT) was $97 \mathrm{U} / \mathrm{L}$. Arterial blood gas analysis showed a $\mathrm{pH}$ of $7.378, \mathrm{PO}_{2}$ of $79.4 \mathrm{mmHg}, \mathrm{PCO}_{2}$ of $32.8 \mathrm{mmHg}$, and oxygenation index of 88.2. The result of interferon-gamma release assay was negative. Hepatitis $B$ virus (HBV) infection indicators: HBV surface antigen 
(+), HBV e antibody (+), HBV core antibody (+), HBVDNA $610 \mathrm{IU} / \mathrm{mL}$. Tests for influenza A virus, influenza B virus, cytomegalovirus, Epstein Barr virus, Toxoplasma, rubella virus, and herpes simplex virus were all negative. Cryptococcal antigen was negative. Galacto Mannan test and $\beta$-D-Glucan test were both negative. All the indicators were negative for routine laboratory screening (anti-nuclear antibody, anti-extractable nuclear antigen antibody, and anti-neutrophilic cytoplasmic antibody, et al) for autoimmune diseases. The number of CD3, CD4 and CD8 T lymphocytes in blood was $76 / \mathrm{mm}^{3}, 44 / \mathrm{mm}^{3}$ and $28 / \mathrm{mm}^{3}$ respectively. Lumbar puncture showed intracranial pressure of $212 \mathrm{~mm} \mathrm{H}_{2} \mathrm{O}$ and CSF was transparent and colorless. CSF cytology and biochemistry showed WBC count $6 \times 10^{6} / \mathrm{L}$, red blood cell count $124 \times 10^{6} / \mathrm{L}$, protein $0.267 \mathrm{~g} / \mathrm{L}$ (normal range $0.15-0.4 \mathrm{~g} / \mathrm{L}$ ), glucose 5.83 $\mathrm{mmol} / \mathrm{L}$ (normal range $2.5-3.9 \mathrm{mmol} / \mathrm{L}$ ), and chloride ions $125.9 \mathrm{mmol} / \mathrm{L}$ (normal range $121.0-129.0 \mathrm{mmol} / \mathrm{L}$ ), adenosine deaminase (ADA) $1 \mathrm{U} / \mathrm{L}$ (normal value: $<40 \mathrm{U} /$ L). Abdominal ultrasound examination found no abnormality. Chest computed tomography (CT) revealed multiple patchy shadows on both lungs and bilateral pleural effusion (Fig. 1A). Head CT scan showed no findings of acute infection or cerebral hemorrhage. After admission, results of two sets of peripheral blood cultures during episodes of fever were negative. Unbiased mNGS of the BALF identified 161 of 79,722 sequence reads corresponding to C. psittaci, there was no sequence read corresponding to other pathogens. Unbiased mNGS of the CSF identified four of 93,308 sequence reads corresponding to C. psittaci (Fig. 2). One sequence read corresponding to candida parapsilosis(C. parapsilosis) in CSF was detected. Clinical laboratory tests and imaging were performed by the department of laboratory and image center of the Third Affiliated Hospital of Sun Yat-sen University, respectively. mNGS was performed and reported by Guangzhou Kingmed Medical Test Center Co.Ltd.. Methods and quality control of mNGS see in Additional file 1.

After admission, the patient was assessed with an acute physiology and chronic health evaluation (APAC HE) II score of 14, sepsis related organ failure assessment (SOFA) score of 8 and mortality risk of $18.6 \%$. She was given tracheal intubation, ventilator-assisted ventilation and anti-infective therapy, together with supportive treatment. Empirical antimicrobial and antiviral agents, including moxifloxacin, ceftriaxone, meropenem, ganciclovir, ribavirin and oseltamivir, were used initially. The peak temperature decreased, but the patient still had a fever. After mNGS of BALF and CSF suggested $C$. psittaci infection, antibacterial agents were switched to targeted doxycycline $(0.2 \mathrm{~g}$ orally on day 8 , then $0.1 \mathrm{~g}$ bid orally on days $8-28)$ combined with moxifloxacin $(0.4 \mathrm{~g}$ qd intervenous drop infusion, days 8-12) and azithromycin $(0.5 \mathrm{~g}$ qd intervenous drop infusion, days 15-21). Meropenem and empirical antiviral agents were ceased since there was no sequence read of bacteria or virus. Her fever was not completely relieved until the use of azithromycin, and finally returned to normal on day 16 after admission (Fig. 3). In accordance with temperature, the neutrophil predominance dropped continuously, along with CRP, PCT and interleukin (IL)-6 (Figs. 4 and 5). She was extubated successfully on day 12 , and was given nasal high flow oxygen therapy after relief of ARDS (Fig. 6). Chest CT scan on day 14 showed multiple patchy shadows in both lungs, partial absorption in the right upper lobe,
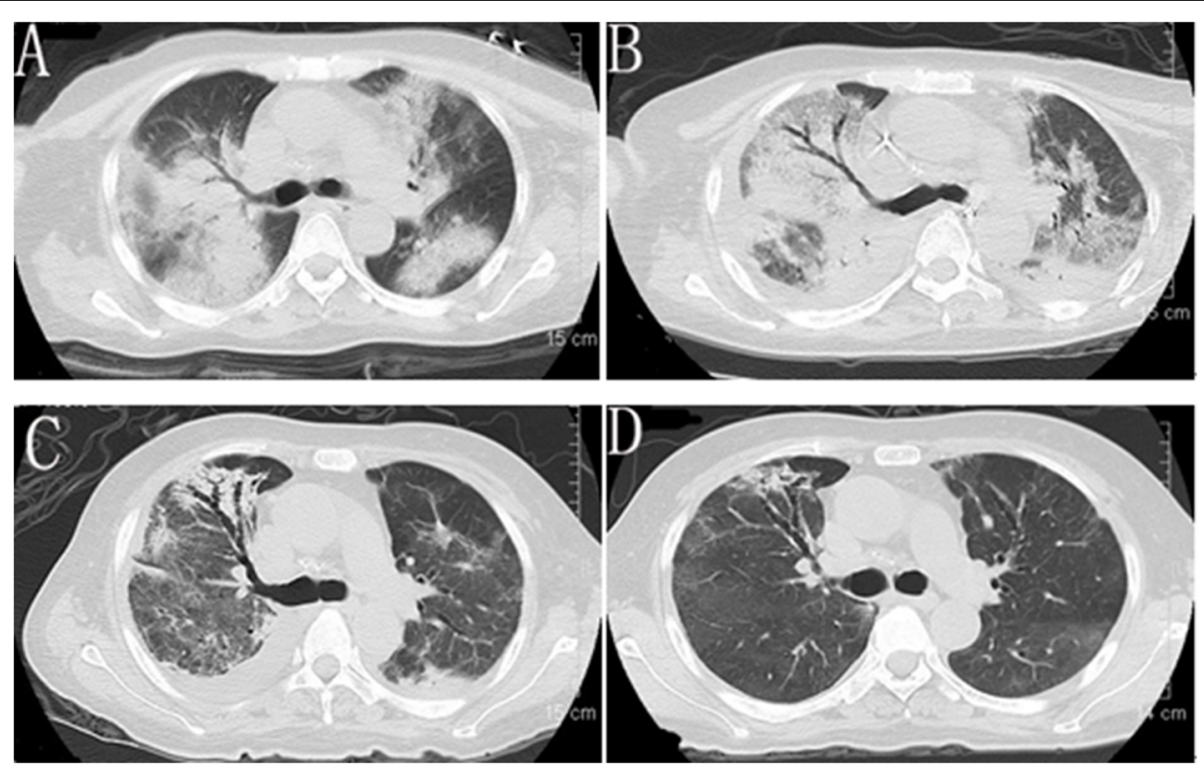

Fig. 1 Chest computed tomography scan at admission (A), 14d later (B), 22d later (C) and 47d later (D) 

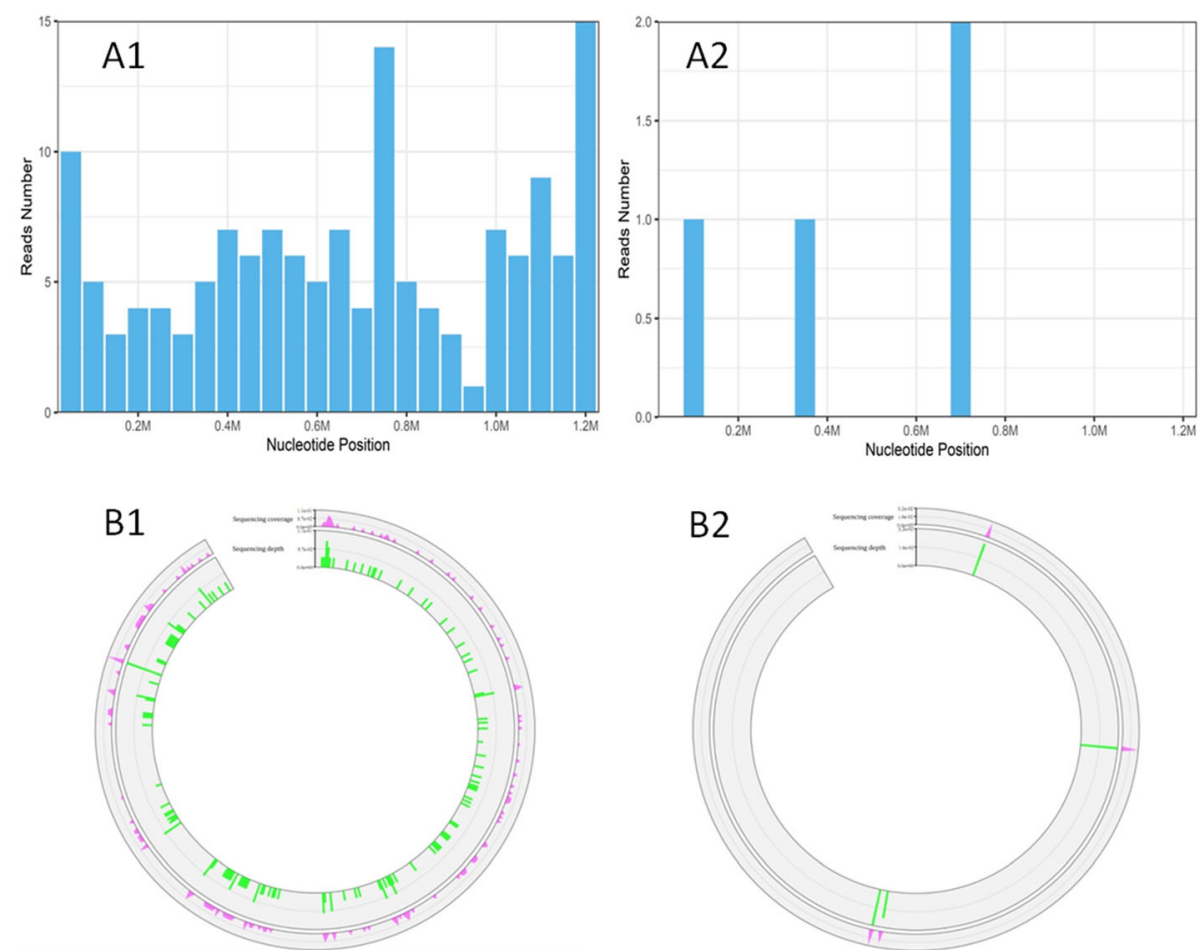

Fig. 2 The cover charts (A1, A2) and Sequencing coverage and depth (B1, B2) of Chlamydia psittaci in bronchoalveolar lavage fluid (A1, B1) and cerebrospinal fluid (A2, B2)

progressive exudation and consolidation in the remaining areas, and increased bilateral pleural effusions (Fig. 1B). The patient was transferred to the Respiratory Department (a general ward) on day 19. The patient's chest CT re-examination on day 22 showed that the bilateral pneumonia was improved, the bilateral pleural effusions increased, and a small amount of pericardial effusion appeared (Fig. 1C). Because her condition improved daily, as well as the increase in oxygenation index (Fig. 6), she was discharged home on day 29 .
The final diagnoses were made as psittacosis, severe community-acquired pneumonia, type I respiratory failure, acute respiratory distress syndrome (ARDS), meningitis, hypothyroidism, and chronic hepatitis B.

She returned on day 47 without complaint. No significant abnormalities were found in inflammatory indexes (PCT, CRP and IL-6) and liver function. Repeat chest CT showed that the exudation and consolidation of both lungs had almost disappeared, pleural effusion on the right side was reduced and the left pleural effusion had

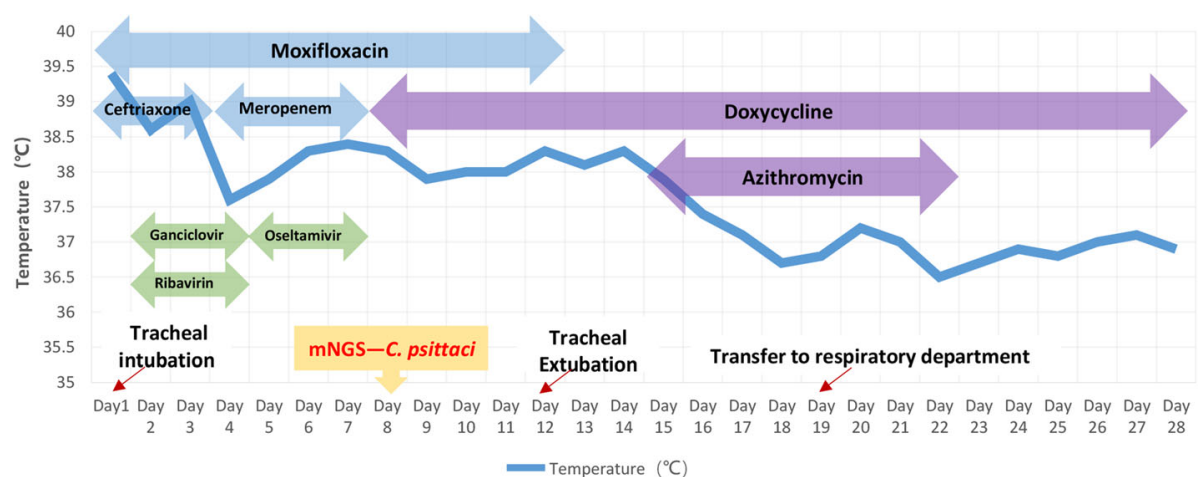

Fig. 3 Body temperature and antimicrobial treatment during hospitalization Moxifloxacin $0.4 \mathrm{~g}$ qd (days 1-12), ceftriaxone $2.0 \mathrm{~g}$ qd (days 1-3), ganciclovir $0.25 \mathrm{~g} \mathrm{q12h}$ (days 2-4), ribavirin $0.5 \mathrm{~g}$ q8h (days 2-4), meropenem $1.0 \mathrm{~g}$ q8h (days 4-7), oseltamivir $50 \mathrm{mg}$ bid (days 5-7), doxycycline $0.2 \mathrm{~g}$ (day 8) and $0.1 \mathrm{~g}$ bid (days 8-28), azithromycin $0.5 \mathrm{~g}$ qd (days 15-21) 


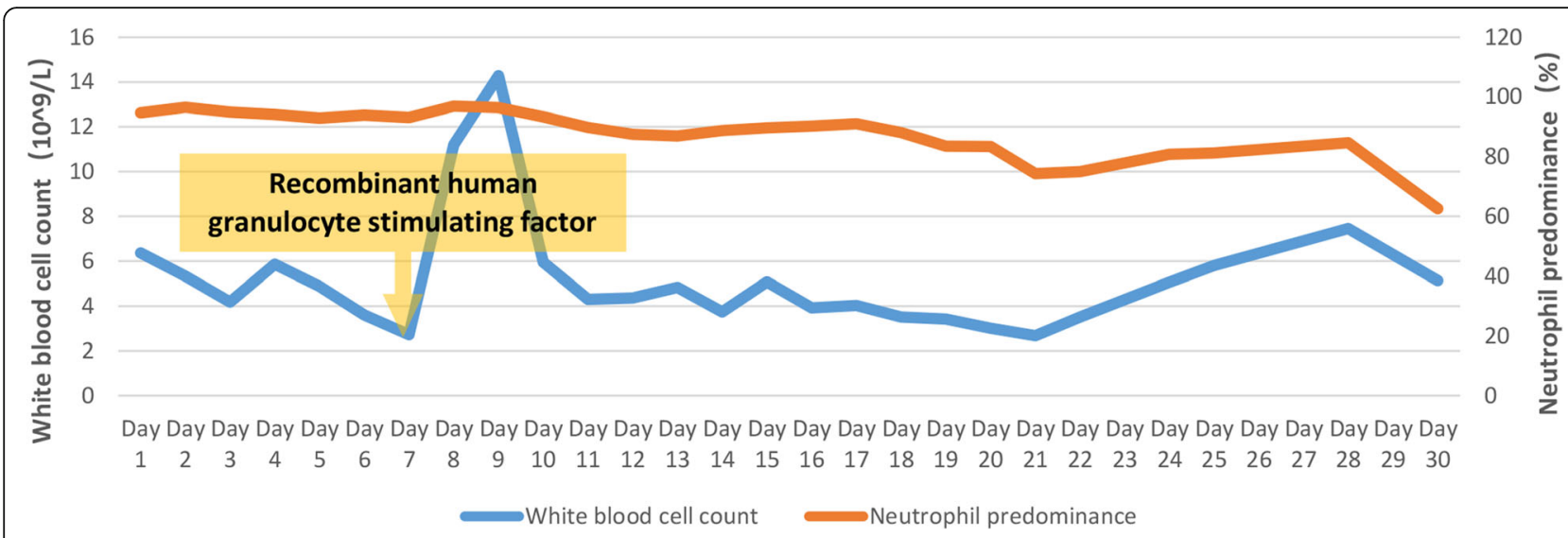

Fig. 4 Change in white blood cell count and neutrophil predominance during hospitalization

disappeared (Fig. 1D). The patient's status returned close to premorbid condition on day 60 of follow-up.

\section{Discussion and conclusions}

C. psittaci, is a Gram-negative, obligate intracellular bacterium that can cause serious psittacosis. Failure to diagnose the disease or identify the pathogen in time, with delayed use of effective antibiotics can cause high mortality in severe cases. Occasional outbreaks of psittacosis cause greater threat to society [2,6]. Although the number of reported cases is increasing, and it has attracted more attention over the past decade, psittacosis is still regarded as an uncommon disease [7]. Due to low awareness and variable clinical presentation of the disease, psittacosis is often not recognized by clinicians, especially among general practitioners. So, it is necessary to discuss and review psittacosis to highlight clinical awareness and management of the disease.

Psittacosis mostly occurs after contact with contagious birds or feathers, excrement, or other substance of sick birds or poultry $[4,6,8]$. Besides, horses are demonstrated a novel source of infection $[9,10]$. Human-tohuman transmission has been reported but it is rare [6].
In this report, the patient denied direct or indirect contact with birds or poultry, nor there was a history of contact with horses. The probable source of the pathogen is unknown in this case.

Most infected people are adults aged 30-60 years, as was the present patient. There is an incubation period of 5-21 days before the symptoms appear. The clinical manifestations vary from asymptomatic infection to multiorgan disease, such as abortion in pregnant women, severe atypical pneumonia, or fatal meningitis in immunocompromised patients $[3-5,11,12]$. Our patient had most of the clinical manifestations outlined below. The onset symptoms usually appear abruptly with high fever, headache, chills, malaise, and myalgia. Mild dry cough can usually be found. Severe cases may involve breathing difficulty as with our patient. Chest pain and hemoptysis are uncommon. Severe headache is prominent in over a third of patients, which may be an indication of the occurrence and severity of meningitis. Fatal meningitis is a not uncommon and severe complication, which mainly manifests as severe headache and mental disorder $[3,4]$. The majority of risk factors in meningitis are head trauma, upper respiratory infection and drug

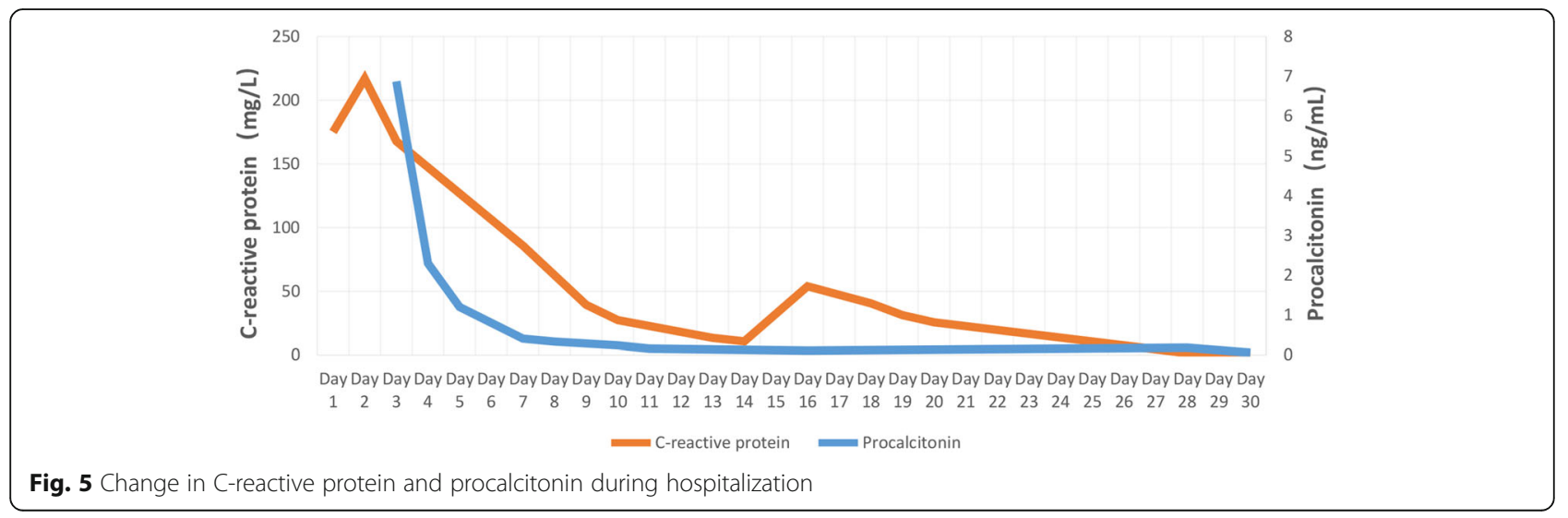




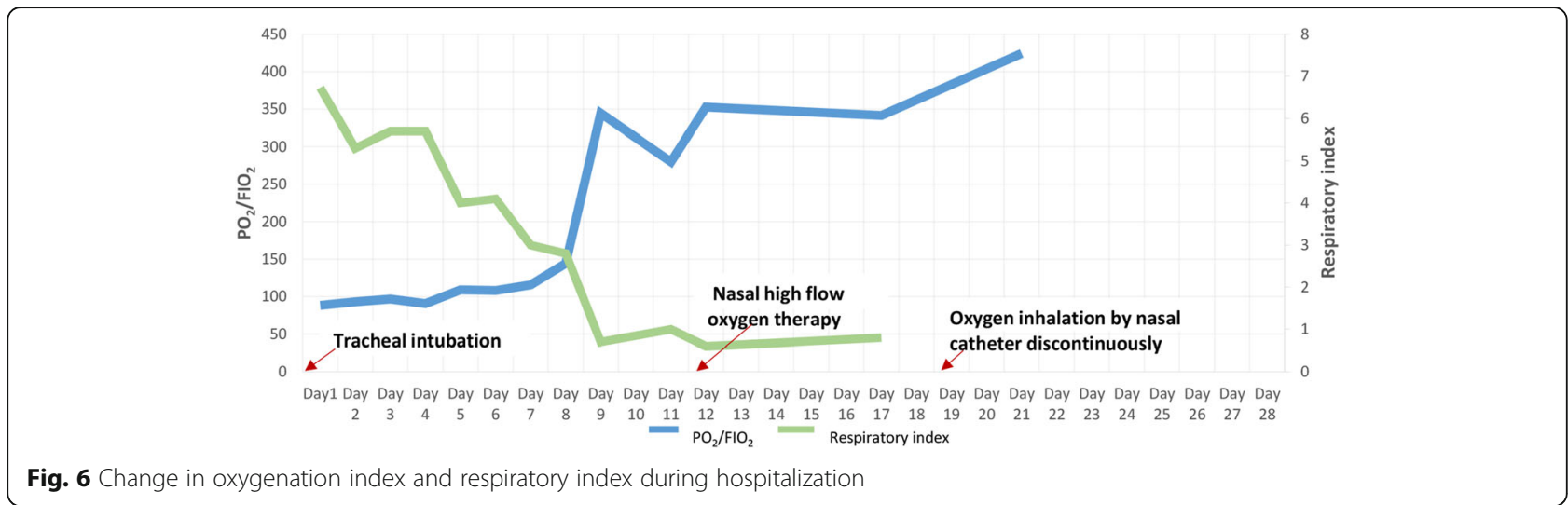

addiction [13]. Our patient had none of the risk factors. The typhoid-like illness with pulse temperature dissociation (fever without increased pulse rate), enlarged spleen, or nonspecific rash case can be sometimes present, although they were not seen in our case. A small number of patients also experience gastrointestinal symptoms such as vomiting, which was seen in our case. High APACHE II score, SOFA score and mortality risk indicated the severity of our patient when she suffered severe pneumonia and meningitis.

More than two thirds of patients' leukocyte counts are within the normal range or at lower level during the acute phase. Inflammation indexes, including CRP, PCT and ESR etc. are elevated in initial blood tests, and are considered as objective markers for effectiveness of treatment, in addition to body temperature. Elevation of serum AST and ALT, which is related to liver injury, is present in some patients $[4,11]$. These laboratory findings are not disease specific, as in the present case. As for the chronic hepatitis B in this case, because her liver function was normal during regular out-patient visit before the onset of psittacosis, which infers that elevation of serum AST and ALT was induced by infection of C. psittaci, it seems it's not a predisposing factor. However, decreased $\mathrm{T}$ lymphocytes in this patient indicated that her immunity was suppressed at the onset of infection, which suggests C. psittaci may prone to cause infections in immunocompromised hosts. As we know, chronic liver disease could cause suppressed immunity. The possibility of chronic hepatitis $\mathrm{B}$ as a predisposing factor could not be eliminated entirely.

Although the radiographic features associated with psittacosis are not sufficiently characteristic to be distinguished from those of other types of CAP, they still show up specificity for atypical pneumonia. Abnormal chest X-rays are present in up to $90 \%$ of hospitalized cases. Chest radiography usually shows different degrees of exudation and consolidation, in which patchy shadows and reticular infiltrations are the most common manifestations. Large shadows on the lung lobes and extensive bilateral pneumonia may also appear in some severe cases, occasionally accompanied by pleural effusion. Chest lesions can be absorbed in 2-4 weeks after medical treatment $[3,4,6,7]$. In this report, chest CT showed extensive bilateral pneumonia with pleural effusion, which was in accordance with severe cases.

The lack of a specific epidemiological history, clinical manifestation and radiographic features makes the diagnosis of psittacosis difficult, which may delay treatment, and sometimes even lead to serious outcome. Psittacosis pneumonia shares many features with CAP caused by viruses, fungi and some bacteria such as Legionella. They all can present with severe headache, high fever, rigors, dry cough and mental disorder, especially in severe cases $[6,14]$. Therefore, the diagnosis of psittacosis needs to be determined by more specific detection $[11,15,16]$. Real-time polymerase chain reaction (PCR) has replaced culture and is regarded as the gold standard for detecting C. psittaci [7, $11,15,17]$. However, PCR is more expensive and has not been developed for convenient use. mNGS can yield a high sensitivity for pathogen identification. mNGS for detection of $C$. psittaci by checking blood, BALF and CSF, etc. is applied clinically [18-21]. Under normal circumstance, there is no co-occurring or opportunistic pathogen in BALF and CSF because they both are aseptic. As we know, C. psittaci does not colonized in human body. Contamination of $C$. psittaci can be eliminated. As long as the process of sample taking, storage and transportation strictly follows aseptic procedures, contamination of other pathogens in BALF from higher airway or in CSF from skin can be eliminated too. mNGS of qualified BALF and CSF specimens help to make an etiologic diagnosis $[19,22]$. In compendium of measure to control C. psittaci infection, additional diagnostic techniques such as genome sequencing are encouraged [6]. In our case, in spite of no definite history of contact with birds or poultry, C. psittaci in BALF and CSF was detected soon by mNGS following strict aseptic procedure and quality control, which supported the clinical diagnosis. There was no other evidence of fungus 
caused infection, one sequence read corresponding to C. parapsilosis in CSF was regarded as false positive. Accordingly, she received no antifungal agents. Besides, mNGS is less affected by prior antibiotic exposure, thereby emerging as a promising technique for detecting such complicated infectious disease [23, 24].

Tetracycline antibiotics are the first choice for treatment of human psittacosis. Mild to moderate psittacosis can be treated with doxycycline or minocycline orally, while severe disease needs to be treated with intravenous doxycycline. Generally, after treatment with tetracycline antibiotics, there is a response within $24-48 \mathrm{~h}$, such as a decrease in body temperature. The course of medication should last at least 14 days, preferably up to 21 days, otherwise insufficient treatment will easily lead to relapse $[4,6,11]$. Macrolide antibiotics, such as azithromycin, are regarded as the best alternative for patients with contraindications to tetracyclines [12]. Fluoroquinolones, such as moxifloxacin and levofloxacin, have also been proven to be effective against $C$. psittaci $[11,25]$. Severely infected patients in life-threatening condition may require combination treatment with tetracyclines, macrolides and quinolones. In present case, the patient achieved good results with targeted treatment of tetracycline orally combined with intravenous infusion of quinolones and macrolides. The corresponding effect and outcome after targeted treatment clinically supported the diagnosis of $C$. psittaci infection.

For this case, differential diagnosis of atypical pneumonia caused by other potential pathogens and autoimmune disease induced acute interstitial pneumonia was eliminated. There was no evidence in cytology and biochemistry of CSF supporting the existence of bacterial meningitis and tuberculosis meningitis. mNGS of BALF and CSF indicated C. psittaci infection. The favorable outcome responding to treatment supported the diagnosis of $C$. psittaci infection strongly. Based on the above clinical data, the etiologic diagnosis of psittacosis, C. psittaci caused severe pneumonia and meningitis was made.

In conclusion, when clinicians encounter patients with atypical pneumonia, accompanied by meningitis with symptom of headache or mental disorder, especially for cases with serious infections but lack response to conventional anti-infective therapy, psittacosis should be taken into consideration. mNGS is a promising detection method in such condition and is recommended.

At last, although it's not sufficient enough for this case report to explore psittacosis and the role of mNGS in the diagnosis thoroughly, accumulation of such report is the need of the hour.

\section{Abbreviations}

C. psittaci: Chlamydia psittaci; mNGS: Metagenome next-generation sequencing; BALF: Bronchoalveolar lavage fluid; CSF: Cerebrospinal fluid;

CAP: Community-acquired pneumonia; MICU: Medical intensive care unit;
$\mathrm{FiO}_{2}$ : Fraction of inspired oxygen; WBC: White blood cell; CRP: C-reactive protein; PCT: Procalcitonin; ESR: Erythrocyte sedimentation rate; AST: Aspartate aminotransferase; ALT: Alanine aminotransferase; HBV: Hepatitis B virus; ADA: Adenosine deaminase; CT: Computed tomography; APACHE: Acute physiology and chronic health evaluation; SOFA: Sepsis related organ failure assessment; IL: Interleukin; PCR: Polymerase chain reaction

\section{Supplementary Information}

The online version contains supplementary material available at https://doi. org/10.1186/s12879-021-06205-5.

\section{Additional file 1.}

\section{Acknowledgements}

We are grateful to professor Jie Qin for offering professional consultation, and thanks Dr. Xiaoxia Chen for helping prepare clinical record. And we really apreciate the guidance by professor Xing Li during the major revision.

\section{Authors' contributions}

SYF and CJX analyzed the data, designed the report and drafted the manuscript; SXH collected the data, reviewed the literature, contributed to manuscript drafting and was responsible for submission, and she is the cocorresponding author; HJJ and LHT made contributions to collect the patient's clinical data; LXJ performed the microbiological analyses; WYH made contribution to clinical management of the patient; WBQ was the leader of the team and was responsible for the revision of the manuscript for important content. All authors read and approved the final version.

\section{Funding}

This work was supported by the Science and Technology Planning Project of Guangdong Province of China, NO.2017A020215177. The funders had no role in study design, collection, analysis, interpretation of data and in writing the manuscript.

\section{Availability of data and materials}

The datasets used and/or analysed during the current study are available from the corresponding author on reasonable request.

\section{Declarations}

Ethics approval and consent to participate

As a case report, our paper did not require any referral to our institutional clinical ethics committee.

\section{Consent for publication}

Written informed consent was obtained from the patient for publication of this report and any accompanying images.

\section{Competing interests}

The authors declare that they have no competing interests.

\section{Author details}

${ }^{1}$ Medical Intensive Care Unit, Department of Respiratory and Critical Care Medicine, Third Affiliated Hospital of Sun Yat-Sen University, Guangzhou 510630, China. ${ }^{2}$ Institute of Respiratory Diseases, Sun Yat-Sen University, Guangzhou, China. ${ }^{3}$ Department of Laboratory Medicine, Third Affiliated Hospital of Sun Yat-Sen University, Guangzhou 510630, China.

Received: 16 February 2021 Accepted: 18 May 2021

Published online: 30 June 2021

\section{References}

1. Cheng Y-J, Lin K-Y, Chen C-C, Huang Y-L, Liu C-E, Li S-Y. Zoonotic atypical pneumonia due to Chlamydophila psittaci: first reported psittacosis case in Taiwan. J Formos Med Assoc. 2013;112(7):430-3. https://doi.org/10.1016/j. jfma.2012.08.017.

2. Shaw KA, Szablewski CM, Kellner S, Kornegay L, Bair P, Brennan S, et al. Psittacosis outbreak among workers at chicken slaughter plants, Virginia and 
Georgia, USA, 2018. Emerg Infect Dis. 2019;25(11):2143-5. https://doi.org/1 0.3201/eid2511.190703.

3. Branley JM, Weston KM, England J, Dwyer DE, Sorrell TC. Clinical features of endemic community-acquired psittacosis. New Microbe New Infect. 2014; 2(1):7-12. https://doi.org/10.1002/2052-2975.29.

4. Yung AP, Lindsay GM. Psittacosis - a review of 135 cases. Med J. 1988;148 228-33

5. Hogerwerf L, De Gier B, Baan B, Van Der Hoek W. Chlamydia psittaci (psittacosis) as a cause of community-acquired pneumonia: a systematic review and meta-analysis. Epidemiol Infect. 2017;145(15):3096-105. https:// doi.org/10.1017/S0950268817002060.

6. Balsamo G, Maxted AM, Midla JW, Murphy JM, Wohrle R, Edling TM, et al. Compendium of measures to ControlChlamydia psittacilnfection among humans (psittacosis) and pet birds (avian Chlamydiosis), 2017. J Avian Med Surg. 2017;31(3):262-82. https://doi.org/10.1647/217-265.

7. Rybarczyk J, Versteele C, Lernout T, Vanrompay D. Human psittacosis: a review with emphasis on surveillance in Belgium. Acta Clin Belg. 2019;75(1): 42-8. https://doi.org/10.1080/17843286.2019.1590889.

8. Hogerwerf L, Roof I, de Jong MJK, Dijkstra F, van der Hoek W. Animal sources for zoonotic transmission of psittacosis: a systematic review. BMC Infect Dis. 2020;20(1):192. https://doi.org/10.1186/s12879-020-4918-y.

9. Jenkins C, Jelocnik M, Micallef ML, Galea F, Taylor-Brown A, Bogema DR, et al. An epizootic of chlamydia psittaci equine reproductive loss associated with suspected spillover from native Australian parrots. Emerg Microbes Infect. 2018;7(1):1-13. https://doi.org/10.1038/s41426018-0089-y.

10. Chan J, Doyle B, Branley J, Sheppeard V, Gabor M, Viney K, et al. An outbreak of psittacosis at a veterinary school demonstrating a novel source of infection. One Health. 2017;3:29-33. https://doi.org/10.1016/j. onehlt.2017.02.003.

11. Stewardson AJ, Grayson ML. Psittacosis. Infect Dis Clin N Am. 2010;24(1):725. https://doi.org/10.1016/j.idc.2009.10.003.

12. Katsura D, Tsuji S, Kimura F, Tanaka T, Eguchi Y, Murakami T. Gestational psittacosis: a case report and literature review. J Obstet Gynaecol Research. 2020;46(5):673-7. https://doi.org/10.1111/jog.14217.

13. Nesami MB. Types, risk factors, clinical symptoms and diagnostic tests of acute adult meningitis in northern Iran during 2006-2012. J Clin Diagn Res. 2015;9(5):IC01-5.

14. Gacouin A, Revest M, Letheulle J, Fillatre P, Jouneau S, Piau C, et al. Distinctive features between community-acquired pneumonia (CAP) due to Chlamydophila psittaci and CAP due to Legionella pneumophila admitted to the intensive care unit (ICU). Eur J Clin Microbiol Infect Dis. 2012;31(10):2713-8. https://doi.org/10.1007/s1 0096-012-1618-6.

15. Nieuwenhuizen AA, Dijkstra F, Notermans DW, van der Hoek W. Laboratory methods for case finding in human psittacosis outbreaks: a systematic review. BMC Infect Dis. 2018;18(1):442. https://doi.org/10.1186/s12879-01 8-3317-0.

16. Fraeyman A, Boel A, Van Vaerenbergh K, De Beenhouwer H. Atypical pneumonia due to Chlamydophila psittaci: 3 case reports and review of literature. Acta Clin Belg. 2010;65(3):192-6. https://doi.org/10.1179/a cb.2010.040.

17. Corsaro D, Greub G. Pathogenic potential of novel Chlamydiae and diagnostic approaches to infections due to these obligate intracellular Bacteria. Clin Microbio Rev. 2006;19(2):283-97. https://doi.org/10.1128/CMR.1 9.2.283-297.2006.

18. Gu W, Miller S, Chiu CY. Clinical metagenomic next-generation sequencing for pathogen detection. Annu Rev of Pathol: Mechanisms of Disease. 2019; 14(1):319-38. https://doi.org/10.1146/annurev-pathmechdis-012418-012751.

19. Brown JR, Bharucha T, Breuer J. Encephalitis diagnosis using metagenomics: application of next generation sequencing for undiagnosed cases. J Inf Secur. 2018;76(3):225-40

20. Chen X, Cao K, Wei Y, Qian Y, Liang J, Dong D, et al. Metagenomic nextgeneration sequencing in the diagnosis of severe pneumonias caused by chlamydia psittaci. Infection. 2020;48(4):535-42. https://doi.org/10.1007/s1 5010-020-01429-0.

21. Gu L, Liu W, Ru M, Lin J, Yu G, Ye J, et al. The application of metagenomic next-generation sequencing in diagnosing chlamydia psittaci pneumonia: a report of five cases. BMC Pulm Med. 2020;20(1):65. https://doi.org/10.1186/ s12890-020-1098-x.
22. Langelier C, Kalantar KL, Moazed F, Wilson MR, Crawford ED, Deiss T, et al. Integrating host response and unbiased microbe detection for lower respiratory tract infection diagnosis in critically ill adults. Proc Natl Acad Scie U S A. 2018;115(52):E12353-E62. https://doi.org/10.1073/pnas.1809700115.

23. Miao Q, Ma Y, Wang Q, Pan J, Zhang Y, Jin W, et al. Microbiological Diagnostic Performance of Metagenomic Next-generation Sequencing When Applied to Clinical Practice. Clin Infect Dis. 2018;67(suppl_2): S231-S40.

24. Fischer N, Rohde H, Indenbirken D, Günther T, Reumann K, Lütgehetmann $M$, et al. Rapid metagenomic diagnostics for suspected outbreak of severe pneumonia. Emerg Infect Dis. 2014;20(6):1072-5. https://doi.org/10.3201/ eid2006.131526.

25. Donati M, Rodriguez Fermepin M, Olmo A, D'Apote L, Cevenini R. Comparative in-vitro activity of moxifloxacin, minocycline and azithromycin against chlamydia spp. J Antimicrob Chemother. 1999;43(6):825-7. https:// doi.org/10.1093/jac/43.6.825.

\section{Publisher's Note}

Springer Nature remains neutral with regard to jurisdictional claims in published maps and institutional affiliations.
Ready to submit your research? Choose BMC and benefit from:

- fast, convenient online submission

- thorough peer review by experienced researchers in your field

- rapid publication on acceptance

- support for research data, including large and complex data types

- gold Open Access which fosters wider collaboration and increased citations

- maximum visibility for your research: over $100 \mathrm{M}$ website views per year

At $\mathrm{BMC}$, research is always in progress.

Learn more biomedcentral.com/submissions 